\title{
Cooperative Learning With and About Internet Forums: A Case Study on a Unit on the Consumption and Chemistry of Mineral Water vs. Tap Water
}

\author{
Johanna Dittmar and Ingo Eilks * \\ Department of Biology and Chemistry, Institute for Science Education, University of Bremen, Bremen, Germany
}

In today's society, digital media play an increasing role in gathering and exchanging information. A growing part of communication takes place in the Internet and many people are increasingly influenced by information provided via digital and social media. Development of critical media literacy is needed, if the general public is expected to effectively deal with this flood of information and to become able to distinguish between correct and false information sources. Thus, critical media education becomes an important aim of education in general, and of chemistry education in particular when considering questions directly related to chemistry and its associated consumer products or technologies. The article describes a curriculum development case study investigating the integration of media education with chemistry learning along the case of learning with and about Internet forums on the topic of water chemistry. A unit integrating theoretical and practical chemistry learning based on student communication is described, which is built around a digital forum operated by Moodle. The unit design and findings from the implementation are presented.

The Open University, United Kingdom

${ }^{*}$ Correspondence: Ingo Eilks

ingo.eilks@uni-bremen.de

Specialty section:

This article was submitted to Digital Learning Innovations,

a section of the journal

Frontiers in Education

Received: 16 July 2021 Accepted: 17 December 2021 Published: 13 January 2022

Citation: Dittmar J and Eilks I (2022) Cooperative Learning With and About Internet Forums: A Case Study on a Unit on the Consumption and Chemistry of Mineral

Water vs. Tap Water.

Front. Educ. 6:742497.

doi: 10.3389/feduc.2021.742497

\section{INTRODUCTION}

In today's developed countries, almost every teenager between the ages of twelve and nineteen has a personal, Internet-enabled mobile phone and uses the Internet on a daily basis (MPFS, 2016). This is why education needs to provide students with critical-thinking skills so that they can safely function in the digital world (Bitkom, 2016). Although performing Internet searches is often viewed as simple and uncomplicated and despite many users' feelings of security in this area, digital information consumption in the Internet requires sufficient care and specific skills (UNESCO, 2013). Even if search engines provide easy, quick access to information, users need to reflect upon Internet information sources and determine both their reliability and their ulterior motives. Users require skills allowing them to deal with digital information safely, critically, and responsibly. They need a fundamental understanding of how different media offerings work. Students should be concerned about developing critical media literacy skills as they "seek to understand, evaluate, use and create information effectively to achieve their personal, social, occupational and educational goals" (UNESCO, 2011). At the professional level, communication has also become increasingly dominated by the digital media (Donelan, 2014; Li and Greenhow, 2015; Uusiautti and Määttä, 
2014). As a result, such media have been suggested as a classroom topic in order to prepare learners for their later professional lives (Krutka and Carpenter, 2016).

Although current digital technologies are almost universally available, there is still debate on how formal education should respond to them (Lewis, 2021). One open question remains as to whether media literacy should be promoted as a self-standing school subject, or should it present a cross-curricular goal for all the school subjects with their various specific approaches to today's society and the natural world, including science and chemistry education (Belova et al., 2017)? UNESCO (2008) proposes equal inclusion in all school subjects. The inclusion of media literacy in education, however, varies significantly across countries (Anderson et al., 1999). Many teachers express a high degree of uncertainty regarding the use of digital media in the classroom when it comes to developing media literacy in their students (Bingimlas, 2009; Hechter and Vermette, 2013). This is in line with the many controversies surrounding media influence on young people (Bennett et al., 2008) and the use of digital and social media sources in schools (Junco et al., 2011; Mao, 2014). While negative influences on young people may indeed be assumed in such cases, a creative approach to the problem is suggested. This is the only way leading to a critical examination of digital media (Hobbs, 1998). Chang Rundgren and Rundgren (2015) or Reid and Norris (2016) have also suggested more intense examination of the mass media in education in general and for science education in particular. Chang Rundgren and Rundgren (2015) state that “. . . media is such an important aspect of modern life, especially for young people, that it needs to have consequences also in the science classroom." They describe a special role for science education when developing critical scientific media literacy. This general claim is valid for all type of media, but challenges science education to take a closer look at digital media, since their influence is continuously growing and they are constantly changing and developing (Hobbs and Jensen, 2009).

This paper describes a curriculum innovation project based on participatory action research (Eilks and Ralle, 2002). The project looks at how the creative application of digital media (in this case digital forums) can be integrated into secondary school chemistry education in order to promote digital media competence. The study analyses the use of digital forums for learning about water chemistry. It circles around the question of whether it is better to drink tap water or bottled (mineral) water. Feedback from both students and teachers is presented in order to recognize potential chances for innovating chemistry education.

\section{BACKGROUND}

The Internet provides information in various formats. These include private and corporate websites, wikis, and social media as only a small sample of the total spectrum of possibilities. Internet forums are included among the many formats. Such forums are platforms used to exchange information between geographically separated people. Questions can be posted, answered, shared, or commented upon by other users who are spatially or temporally removed from the inquirer. Discussion threads found in forums often combine questions with facts, personal experiences, opinions, and beliefs. Forums represent a question-and-answer system, which can be used at any time to get quick responses or to comb through earlier responses to and opinions about certain questions. Internet forums belong to the many social media offerings that are defined by the provision and access of information for and by the general public, including the exchange and establishment of relationships (Schmidt and Taddicken, 2017).

There are numerous forums on the Internet. These include general forums open to almost every topic or interest, as well as diverse domain-specific forums. Generally, the number of users in general forums tends to be significantly higher than in most domain-specific forums. In domain-specific forums, however, there is a greater likelihood of users meeting other people with the same interests or professional backgrounds. In a domainspecific forum such as those focusing on chemistry, not only laypersons but also chemistry students, teachers or professors contribute to forum writings. A study in Germany has shown that teenagers between the ages of 12 and 17 have usually know the major general Internet forums in their language, but domainspecific forums in chemistry remain largely unknown to them (Dittmar and Eilks, 2019).

Internet forums provide us with new perspectives for teaching and learning (Liu, 2010; Gikas and Grant, 2013), since information provided can be handled in different ways (Selwyn, 2012). Forums can support learning, since answering questions about teaching problems is no longer dependent on lesson time or the physical presence of the teacher (Uusiautti and Määttä, 2014). After lessons are over, learners can easily discuss or deepen their knowledge of issues which are spatially independent (Schaumburg and Issing, 2004). Knowledge can be developed in interaction with others and contribute to the overall learning process (Brown et al., 1989). In addition to the spontaneous use of forums, the learning process can be supported by various forms of communication which include the views expressed by both layman and experts (Krutka and Carpenter, 2016). Cross-school interactions can also take place (Gikas and Grant, 2013; Mao, 2014), which have already been suggested as one way to strengthen learner engagement in the learning process (Murphy and Lebans, 2008).

Up until now, Internet forums have not been very prominent when considering social media contributions in chemistry education. Dittmar and Eilks (2019) inquired the way that learners deal with Internet forums. The study showed that students are acutely aware of digital online forums. Learners tend to increase their use of digital forums with age. The students, however, expressed a very critical stance towards Internet forums. They were insecure about the reliability of information found in forums, although it has been described in the literature that the overall quality of information located in such forums often is to be considered appropriate (Cole et al., 2016). In the Dittmar and Eilks (2019) study it became quite apparent that most German secondary school students remain passive consumers of Internet forums. Very rarely did they themselves post questions or actively provide comments. 
In Internet forums information is put up for discussion in order to inform oneself or to exchange opinions and experiences. Often, a variety of people participate in such discussions and write contributions, whether they are knowledgeable or not. Accordingly, it is not only important that contributions from the media are tested for reliability, but also science as a possible source of information in the media is critically scrutinized (Belova et al., 2015). It is suggested that professional and strategic use of Internet forums can be quite advantageous (Raymond and Moen, 2014). In terms of a creative approach to media literacy in chemistry education (Hobbs, 1998), teaching strategies are needed that actively involve students to foster understanding about the structure and potential of digital media offerings, like digital forums. Also OECD $(2005 ; 2018)$ calls for interactive use of media so that the learner can keep up with the latest state-ofthe-art, use these tools, and deal with them actively.

Internet forums or contributions from Internet forums can be used in a variety of ways for teaching chemistry. In the case of advertising, Belova and Eilks (2015) showed that media entries can be used for an authentic or motivating unit opening, but also for the contextualization of tasks and experimental investigations. The same holds true for digital and social media entries. Offerings in the media can also be used to question the role of science as a source of relevant information in public discussions and to show how science is presented and used in the media. Similar to advertising, these applications can also be carried out with social media in general, and Internet forums in particular (Dittmar and Eilks, 2015). In order to meet the educational requirements of interactive media use (OECD, 2005; 2018), application of digital forums should not stop at merely reading their contributions or with presenting them in class. The OECD (2005) or Reid and Norris (2016) have suggested learning about various media offerings by making active use of them in class. This is why this action research case focused on enriching the pedagogy in science education by making students active users of Internet forums as a contribution to media education to see how students react to it. The question of water quality is used as a case that is scheduled in the regional syllabus for the first year of upper secondary chemistry education. In the regional syllabus, it is suggested to learn, and deepen knowledge from lower secondary education, chemical concepts behind the chemistry of water (e.g., the structure of the water molecule, intra- and intermolecular forces, solubility, dissolved substances in different kinds of water, etc.). Beyond, the syllabus suggests introducing students to ideas of clean water supply and the quality of drinking water. The issue of clean water supply is connected to the question how safe it is to drink tap water in Germany. Tap water in Germany is of very high purity and quality is very much controlled (The Local, 2019). The question leads over to further discussion whether to better consume tap water or buy the by far more expensive bottled water (UBA 2018), a question that is regularly raised in advertising or discussion in the general public. Public discussion takes place both in more conventional media (e.g., The Local, 2019) as well as in social media, such as Internet forums (e.g., gutefrage.net, 2021), where the latter is very prevalent in the media habit of the young generation (Dittmar and Eilks, 2019). The aim of the action research case reported in this paper was to develop a teaching and learning scenario for chemistry education using digital forums for both structuring students' communication and allowing them to learn about communication in digital forums in the case of learning about water supply and quality. The focus of the research is to better understand how students engage in such an activity and respond to it in terms of their perception and motivation.

\section{METHOD AND SAMPLE}

The unit for this study was developed using participatory action research as suggested for chemistry education by Eilks and Ralle (2002). The initial unit was designed by an active chemistry teacher (J.D.) and presented to a group of teachers who have been working on curriculum design and action research for more than 20 years (Eilks, 2018). The design was negotiated and refined in monthly meetings. At the end of the design process, the unit was tested in a total of seven learning groups (age range 15-17). Three tests were carried out in grade-10 comprehensive school chemistry classes (the last year of the lower secondary schooling level); four test runs took place in grade-11 grammar school chemistry courses (the first year of the upper secondary schooling level). A total of 138 students participated in the study (70 female, 66 male, 2 no response). The designer of the unit (J.D.) carried out three of the trial runs herself. The other tests were taken over by teachers in the authors' wider educational network. One class taught by J.D. was using a second teacher as an observer. Of the other four classes not taught by J.D., all were accompanied and observed by the first author of this study. All data was collected anonymously and on a voluntary base. All legal restrictions on data collections in schools under the regional law for schools were respected.

Feedback from the learners was collected using a questionnaire asking about their perceptions of the unit, similar to the tools used in Marks and Eilks (2010) or Belova and Eilks (2015). The questionnaire recorded information about gender, class level and school type. Questions about student feedback consisted of three open-ended questions and ten Likert items (four step). In the open-ended questions, the learners were first asked what they considered to be essential things that they had learned during the unit. In the other two open-ended questions, the learners were supposed to describe any aspects that they particularly liked (or not). The Likert items focused on the learners' general perception of the unit. Questions basically referred to perception and motivational issues.

The open-ended questions were analysed using qualitative content analysis according to Mayring (2000). Likert items were subjected to descriptive statistics as suggested for this kind of educational design work, e.g., by Bodner et al. (1999). In the case where a second teacher was present in class, the additional teacher filled out an observation sheet to provide information to triangulate students' responses. The observation sheet had two foci, namely the students' behaviour and the how the teaching methodology worked. Four questions focused on student activity in terms of indicators of student engagement, small group interactions, inter-group interactions, and indicators for 
TABLE 1 | Overview on the unit.

Content

Lesson periods

Preparation of the forum work

Posing the opening question

Overview of the unit

Forming cooperative learning groups

Introduction to the pedagogy and digital forum use

II Cooperative working phase

Contention with the groups' learning aims using worksheets and practical work

Developing questions and information

At different steps: Posting questions and exchanging information in the forum (visible to the whole class by a digital projector

on a whiteboard)

III

Reflection of the forum work

1

Discussion about learner experiences, problems and the chances of using a digital forum as a tool for connecting the work of

different cooperative learning groups

Feedback questionnaire

mutual support. Five questions focussed the methodology, namely on the introduction, technical issues, indicators for students' perception of the method, students' behaviour in the final discussion, and suggestions for improvement. This data was also subjected to qualitative content analysis according to Mayring (2000).

Open ended responses reported in this paper were translated by a native speaker who studied both in the United States and Germany. He is now working as an English language and science teacher in a German school for about 15 years.

\section{THE INTERVENTION}

The unit is comprised of six lesson periods (45 min each) and has three phases (Table 1).

The focus of the unit is the chemistry of water, a topic taken from the regional syllabus in northern Germany, which is relevant for the school classes involved. With reference to the socio-critical and problem-oriented chemistry curriculum model (Marks and Eilks, 2009), the unit addressed an authentic and societally relevant question. In most countries of the world, drinking tap water is not recommended because of potential health risks. In many developed countries, however, tap water is of the highest quality. This is the case in Germany. Under German legislation, a distinction is made between five types of drinking water, namely: mineral, medicinal, spring, table, and drinking/tap water. In Germany, drinking water from the tap is at least as strongly regulated as the other four types of water and can be drunk without any risk to human health (UBA, 2018). In Germany, tap water is the safest, most regulated beverage/food product (Tappwater, 2019). Therefore, consumers debate among themselves whether to pay for bottled water or to simply drink tap water, either pure or as carbonated by a soda streaming device. But which measures influence consumers when deciding which type of water to drink? What are the options consumers have to inform themselves? This question concerns, among other factors, issues of personal taste, the degree of mineralization of the water, price considerations, and the environmental aspects of bottling water. The decision is also influenced by the large number of

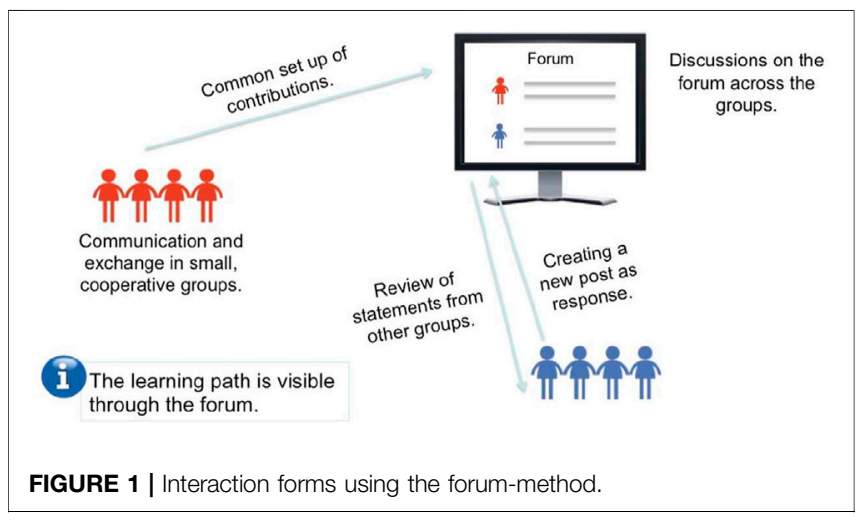

available mineral water brands, with a plethora of different labels and advertising measures on the one hand, and companies actively advertising particular water-filtering or soda streaming devices on the other.

In Germany, public media and advertising offerings ask whether it is better to drink bottled water or tap water in order to influence consumer choice (e.g. The Local, 2019). Both public media and advertising present a variety of promises for both possibilities. Bottled water represents by far the more expensive choice (UBA, 2018). This is why bottled water makes use of advertising promising alleged better taste, claiming high purity, or praising the "naturalness" of the water source. On the Internet, a wealth of websites can be found on which advertisements for different bottled water brands appear and the corresponding aspects of product quality are discussed. The discussion often appears to be supported by seemingly professional scientific information, whereby the distinction between scientifically sound and unsound information often is difficult for consumers to evaluate for themselves.

In the unit presented here, the leading action research teacher (J.D.) decided to focus on Internet forums and to connect them to learning about water chemistry. The idea was that the interaction between smaller cooperative learning groups could take place exclusively via a digital forum (Figure 1). 
TABLE 2 | Group-specific topics of the unit.

\begin{tabular}{ll}
\hline Group 1 & $\begin{array}{l}\text { Key ingredients in water for human nutrition } \\
\text { Categorization of drinking water types } \\
\text { Examining a drinking water filter cartridge }\end{array}$ \\
\hline Group 2 & $\begin{array}{l}\text { Dissolved matter in water } \\
\text { Water treatment steps for preparing tap water } \\
\text { Preparation of a water filter }\end{array}$ \\
\hline Group 3 & Compounds in water and water hardness \\
& Drinking water analysis \\
& Detection of nitrates, nitrites, copper and pH \\
Group 4 & Ingredients according to German drinking water regulations \\
& Features of water quality \\
& Electrical conductivity and pH of various water samples
\end{tabular}

In the preparation phase the students were confronted with the question: "Mineral water or tap water: which is better?" A brainstorming of viewpoints was then carried out, in order to call up students' prior knowledge and experiences. The learners also reflected upon which criteria might influence a person's decision. A selection of contributions taken from authentic public Internet forums was then presented to them, which showed different points of view on the topic. This was done to illustrate the authenticity, societal relevance, and versatility of the topic (On the familiarity and perceived reliability of public digital forums to secondary school students see, e.g. Dittmar and Eilks, 2019). Arguments from Internet forum offerings were identified and structured, in order to provide the participants with an overview and to reveal any potential questions. This phase ended with the forming of small groups for cooperative learning and the introduction of a digital forum set up using Moodle. To provide the students a safe space for learning the digital forums were open for each of the learning groups only. They were only accessible by the teacher and each of the classes during the teaching time of the unit. This was justified by the finding that secondary school students generally are reluctant to actively contribute to public forums (Dittmar and Eilks, 2019).

In the second phase of the unit, information was provided by different worksheets and further explored by practical work. Information provided by the different groups was structured to complement the other subtopics (Table 2). Certain tasks in each group were constructed in a way that required gathering information from other groups in order to solve them. The recommendation was made to steer the interconnected exchange of information by posting questions in the forum and asking for answers and suggestions from the other users. The basic chemical knowledge for all of the groups was, however, identical. Students needed to understand water as a polar substance, the dipole nature of the water molecule, the concept of dissolution, and identities of the minerals present in the different sorts of water. Experimental results, tables, and diagrams were also to be used. Internet searches were carried out to determine regional water quality.

After the students started working on the material, an initial forum question was posted by the teacher. A fictitious user asked the forum members: "Hello! I drink about $2 \mathrm{~L}$ of tap water daily. My neighbour told me that I shouldn't, because there are no nutrients at all in tap water and it may even be unhealthy. Is this correct? Should I drink mineral water instead? And if so, which one? What things should I pay attention to? Thank you."

In the thread to the initial question, the cooperative learning groups were asked to bring all of their knowledge to bear and to connect the information coming from different groups together. Since all of the student groups were working on slightly different topics, each was able to contribute different perspectives to the overall question. The goal was to provoke a discussion between the small groups in the forum. Contributions to the forum were to be formulated within the small groups and posted together. The learners were expected to discover that communication in a digital forum is very different from personal, face-to-face communication. Working in the digital forum also aided in the exchange of experimental results with the aid of photos, diagrams, and tables.

In the final phase of the unit, the overall learning process was reflected upon. The focus of the reflection phase was to find out whether one-sided considerations or arguments had been given due to the different viewpoints of the small groups. The students' learning path was also discussed using the forum thread, which also was provided to the students. In this context, various arguments could be filtered out of the forum thread in order to explain different points of view among the pupils. The final phase was also used to sensitize the students' concerning their awareness on distinguishing correct and potentially misleading information in digital forums with the aim to contribute to their skills in dealing with digital media safely and responsibly.

\section{FINDINGS AND DISCUSSION}

\section{Students' Feedback in Open Questions}

More than half of the learners $(N=86)$ indicated that the content matter about water chemistry was the most important thing that they had learned during the unit. The students felt that they could understand the differences "between tap water and mineral water, more detailed information on tap water and mineral water, as well as the advantages and disadvantages of tap water and mineral water." They also felt that they had gaining competency in Internet usage ("it is worthwhile to look at the Internet for a while"). A few learners also stated that they had come to a personal decision on mineral water or tap water (" $I$ got an impression of which water is better or worse for me"). Almost $30 \%$ of learners $(N=40)$ said that they had learned a lot about the contents of mineral water or tap water. They thought that it was important to deal with such issues: "The most important thing for me was the conceptualization of water, what can be in it, and what to look for." Group-specific topics (regional characteristics of the water supply, water quality, drinking water regulations, water filtering, and water hardness) were mentioned more frequently than the basic chemical properties of water (e.g. molecular structure or particle-particle interactions). This may be an indicator of learners showing more interest in information that is directly related to their everyday lives (Childs et al., 2015). Nevertheless, there were also some students $(N=9)$ who mentioned basic chemical content, such as the dipole 
nature of the water molecule, issues of dissolution, and hydration. Aside from the chemistry aspects, several participants also stressed the importance of learning about dealing with Internet forums and critically addressing them: "to discuss topics from forums and to ask questions, how to work with forums, how to use a forum correctly."

Overall, the feedback from the learners on the unit was quite positive. The majority of the students expressed a positive view of the unit, with almost $60 \%$ of learners $(N=81)$ expressing no criticisms in the open-ended, follow-up question about the unit. The methodology was also generally positively assessed. Almost $40 \%$ of the students $(N=44)$ mentioned the work in the forum as a learning tool: "In my opinion, content can be better understood by Internet forums (simple language, different views, etc.)." The indirect method of communication was perceived to provide more personal freedom in learning. It gave a "relatively large amount of free space to work at one's own pace and we did not always have to maintain high levels of concentration." "One was free to work but had rules, nevertheless one could freely decide what to write (within the guidelines) and what one's own opinion would be." More than half of the students $(N=63)$ indicated that they had enjoyed working in small groups, with an emphasis on freedom in working such groups: "I could work by myself, but also exchange information in the group." This falls in line with previous research on cooperative learning evidencing a wide range of effects on student learning (Lazarowitz and HertzLazarowitz, 1998). Students also had positive views about the practical tasks in combination with working on the computer. Ten percent of the learners $(N=11)$ also mentioned that they really liked the topic and the related discussions of a relevant, everyday issue: "The everyday topic, the exchange of information via forum, and the final discussion."

Some methodological $(32 \%, N=18)$ and technical issues $(18 \%$, $N=10)$ were negatively mentioned in the feedback. Some students felt overwhelmed $(18 \%, N=10)$. Others mentioned individual problems with the group work $(18 \%, N=10)$. One critical concern with respect to the digital forum was the waiting time before receiving an answer, as compared to simply asking the teacher for confirmation. In order to shorten the waiting times, it was suggested that the teacher should be more active. Some groups also criticized the fact that "argumentation/ discussion between the groups was missing. A kind of personal debate would have been good. There was no real full-group discussion in the forum." Negative issues pertaining to the method were more prevalent in the 10th grade comprehensive school classes than in the 11th grade grammar school classes. Issues with the method might, however, be reduced by multiple applications of digital forum use in class.

The results from the open-ended questions indicate that digital forums link many motivating teaching elements together. The students felt more in control of their own learning time and could independently decide which tasks are to be worked in which order. The exchange of opinions and experiences made this lesson an especially well-perceived teaching experience: "We dealt with the practical tasks, which were then evaluated. Then we formed our own opinions, which we presented in the forum and we also received different opinions."
Overall, there were no trends observed between male and female students.

\section{Students' Responses to Likert Items}

The generally positive perceptions in the open-ended questions were also mirrored in the Likert items (Figure 2). Although the learner groups were working with digital forums for the first time in class, about $70 \%(N=94)$ expressed a positive attitude towards the approach in the corresponding items $1-10$. They wanted to use the approach more often in the classroom. In one item, more than $80 \%$ of the students $(N=113)$ clearly expressed a wish to work with digital forums in class. Discussion $(N=103)$ and exchange $(N=104)$ in the digital forum were positively perceived by the majority of students. More than half of the learners $(N=$ 74) perceived the method as supportive of their participation in learning.

With regard to contributing to critical scientific media education, nearly half of the participants $(N=62)$ stated that they had developed a more critical view of Internet forums and that they had reflected upon their personal opinion of which type of water to drink. This is only half of the students. It is, however, unclear how much they had thought about the topic before the unit. Generally, many students already assess themselves as being critical towards Internet forums and posts (Dittmar and Eilks, 2019). Therefore, an improvement among half of the students can be considered a success.

\section{Classroom Observations}

The classroom observations also support the general positive perceptions of the applied pedagogy. The observers, in the observation sheets, documented a motivating learning atmosphere: "They were curious, because as soon as something new is implemented, the students are usually a bit more alert." The observations described "a good/high willingness to work, high motivation, students found the topic exciting and easy because it is an everyday issue." This was supported by ideas that the learners were motivated by the unit opening using authentic forum contributions, which were borrowed from a real forum (gutefrage.net; the largest and most popular Internet forum in German). The learning environment was characterized as providing room for autonomous work among the learners.

The learners seemed to react differently to the Internet forum. Many students seemed to have to familiarize themselves with the technical situation first and apparently "not everyone in the forum was really in it, and the forum was not as familiar to them as everyday business." It seems that many learners only read in Internet forums and that they were much less familiar with actively contributing to forums, as has been described in Dittmar and Eilks (2019). These learners first approached the forum cautiously and spent a great deal of time in the formulation of any contributions, however, the resistance decreased with time.

Reflections on pro and con arguments from the forum turned out to be difficult for many learners. The students were able to grasp the arguments, but when they "had to reflect upon them again, they had difficulties." This finding can be attributed to the complexity of evaluating the different water offerings in the Internet: "Moreover, it was difficult for the pupils to accept that 


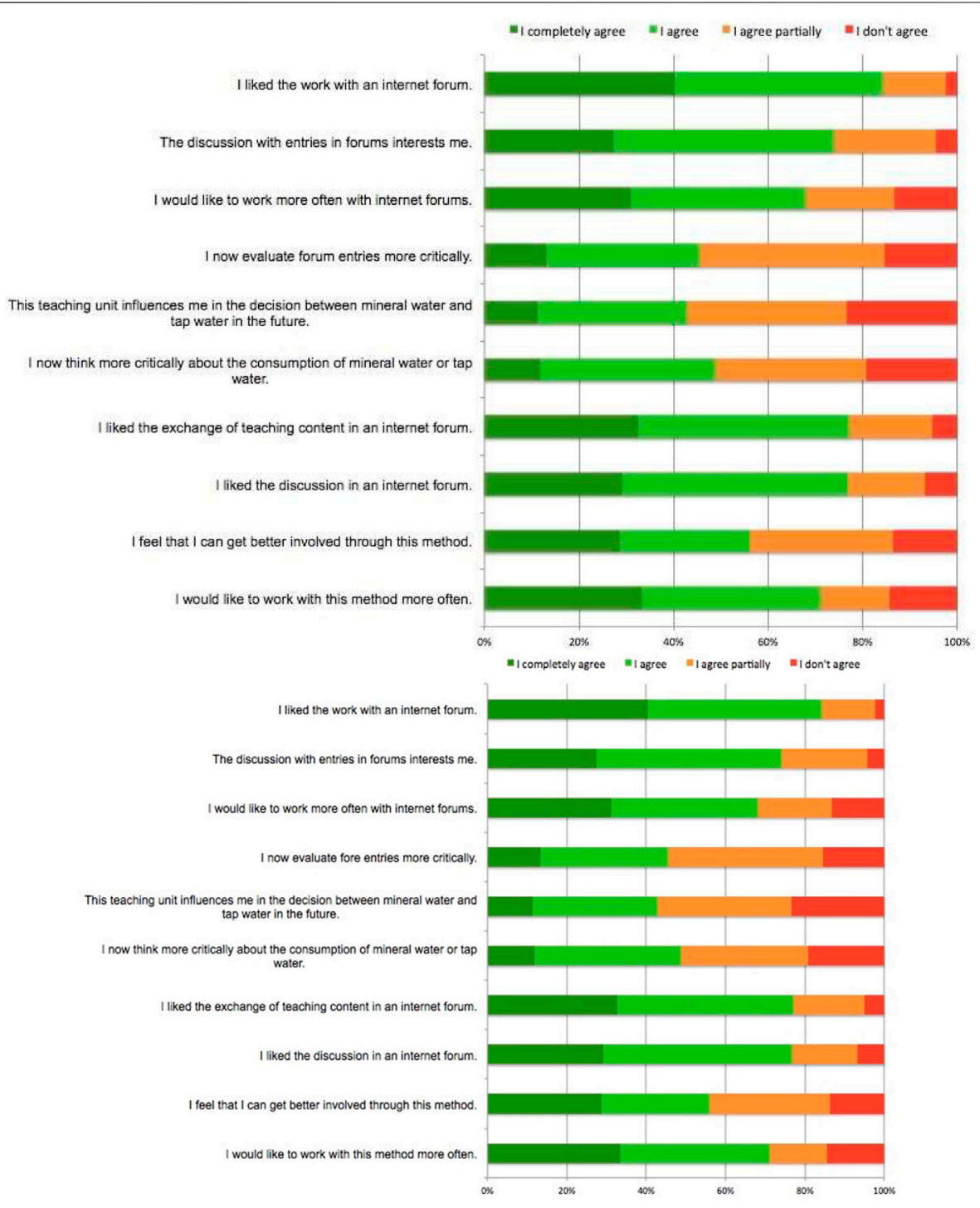

FIGURE 2 | Results from the Likert questionnaire ( $N=138)$.

there is no final decision for or against a certain type of water." The learners discussed different topics within their small groups, but their information overlapped with information from other forum groups to only to a certain extent. Each small group had to link their arguments and information. It also had to compare and evaluate their information with regard to the forum posts of other groups. This was viewed as a difficult task for some of the learners.

Concerning the groups' interactions, the students performed well in small groups as far as it could be seen by observation. Especially at the beginning the students worked with a clear focus. In the forum, however, it was readily observable that the level of interaction needed to be improved. This observation provides a good argument for employing digital forums more often in classroom settings in order to provide chances for students to practice and gain experience: "That argument was not so profound, because they played a lot." A few learners questioned the forum work and did not understand the reason for implementing the forum pedagogy: "Why do we need the forum at all? We can also talk personally." Other learners, however, expressed an understanding of why they should work in a forum. They discussed the advantages of communication via forums over longer distances and in the case of spatial separation. Forum communication was considered to be easier to manage with other learning groups in the room.

In the observations the students were described as "thrilled that something else was coming." The pedagogy was viewed as "already beautiful. I believe they will remember it. This simply motivates them to unpack their mobile phone in class." However, the learners who accessed the forum via their personal mobile phones did encounter some technical limits, which they stated in the questionnaires. Students' mobile phones might be better used as a supporting tool only in addition to a laptop computer or 
tablet. Overall, from the observation it is suggested that the methodology generally had been well received by the learners: "So yes, in the one class it was really good with the forum, mostly because they also reacted outside the classroom. And days later, so it was not only in the break afterwards, but also on the weekend." However, it is also suggested that digital forum use in class needs to be trained: "The more you use the method, the more you know what is required of you."

\section{Communication in the Forum Threads}

Each learning group created a forum thread. In the course of the various threads, there was a different set of questions, answers and other comments (Table 3). A total of 185 posts were written in the seven forum threads, with an average of 26 entries per learning group (varying from 14 to 46 entries).

Most of the contributions from the learners focused the topic of discussion (71\%), either by asking questions (10\%) or providing answers (61\%). The teachers supported the communication by about $20 \%$ of the entries in the means of asking further questions. Other reactions by the learners only occurred in $7 \%$ overall. These were comments not directly related to the discussion about the content.

The forum provoked dialogue both between the teacher and the learners and among the learners, with different groups being involved showing the progress in understanding the topic in group 1 . The following excerpt from the communication in one of the threads may serve as an example:

Ms. AquaBest (the teacher): Hello! I drink about $2 \mathrm{~L}$ of tap water daily. My neighbour told me that I shouldn't, because there are no nutrients at all in tap water and it may even be unhealthy. Is this correct? Should I drink mineral water instead? And if so, which one? What things should I pay attention to? Thank you.

Group 1: Hello, tap water can be harmful, e.g. if there are still old lead pipes in the house. It is also possible that tap water is contaminated by filters. It is also possible that tap water contains little or no minerals. We would advise you to drink mineral water, as it contains more minerals and helps with deficiency symptoms, but we would recommend drinking mineral water from glass bottles rather than plastic bottles, as plastic bottles contain "plasticizers", which are suspected to be carcinogenic. Best regards.

Group 2: Dear group 1, on your claim that mineral water is better than tap water because the tap water is polluted by filters, we can refute this argument by saying that tap water is tested for many different substances at any time. \#Clean water \#InThisSense Sincerely.

Group 1: Hello, the water suppliers are obliged to carry out regular checks to ensure that the legal regulations and limit values are observed. There are limit values for over 40 different substances and parameters. But, are the test criteria clearly defined? Is the Drinking Water Ordinance up-to-date or does it even have gaps? There are neither limit values for drugs and their residues; nor for hormones. This means that many foreign substances are hardly or not at all filtered out.

Source: http://wwwl.wdr.de/fernsehen/quarks/ sendungen/sbtrinken $142 . \mathrm{html}$

Here you will find more information. \# In this sense, have fun reading Greetings.

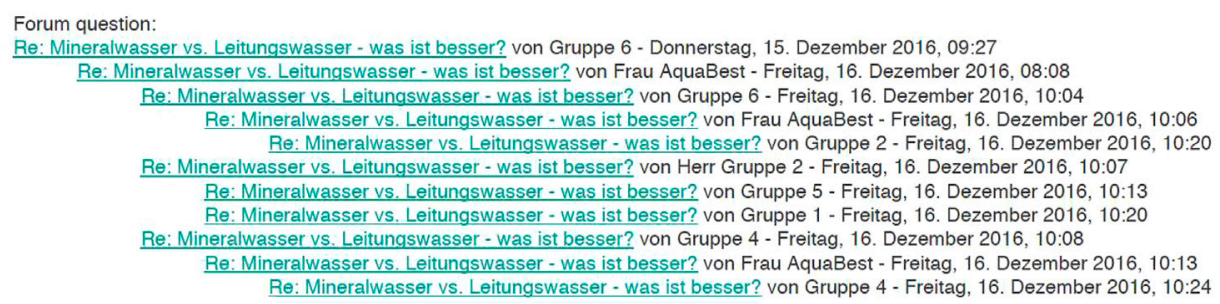

FIGURE 3 | Part of a forum thread showing a communication involving different student-groups and the teacher (Gruppe, German for group; Frau AquaBest, the teacher).

TABLE 3 | Distribution of forum posts.

\begin{tabular}{|c|c|c|c|c|c|}
\hline Learning group & Forum posts & Questions (teacher) & Questions (students) & Answers (students) & Other comments \\
\hline 1 & 34 & 8 & 3 & 22 & 1 \\
\hline 2 & 46 & 5 & 4 & 30 & 7 \\
\hline 3 & 27 & 7 & 2 & 15 & 3 \\
\hline 4 & 37 & 11 & 0 & 22 & 3 \\
\hline 5 & 11 & 1 & 3 & 6 & 0 \\
\hline 6 & 16 & 4 & 1 & 11 & 0 \\
\hline 7 & 14 & 0 & 6 & 7 & 0 \\
\hline
\end{tabular}


$35 \%$ of the learners' communication in the seven forums concerned a direct exchange with the teacher. In $38 \%$ of the cases another learning group was involved in the discussion. In further $20 \%$ of the discussion in the thread more learning groups took part in the communication. In $5 \%$ of the communications almost all students were involved (Figure 3).

\section{CONCLUSION}

In today's modern society, contemporary education needs to include digital and social media and the content they represent. Chemistry needs to be part of it to enrich students' views on the world they live in (Sevian and Bulte, 2015). Such digital and social media education cannot end with merely consuming media or reflecting upon media content. It also needs to shape media creation skills and encourage learners to actively contribute to media offerings (UNESCO, 2011). Such media education is a cross-curricular goal, which every school subject should strive to achieve, including science and chemistry education (Belova et al., 2017). The example described in this paper shows a case study combining chemistry learning with digital media education with the help of digital forums in class. Although there are several limitations in this study, including a purely German background, a specific age level, and just one topic taught, some promising indications were still found. Feedback from students and classroom observations indicate that digital media offerings provide chances for enriched and motivating pedagogies in chemistry teaching. Even this short intervention showed that many students were reluctant to actively contribute to a digital forum in the beginning; they, however, overcame this hurdle in contributing to media with time and practice. It is, however, that further refinement of the lesson plan may help to support higher activity and interaction amongst students. Maybe, this motivates them to become more active in digital forums outside the classroom, too.

More research and curriculum development is needed in this area if we wish to create further examples. This would allow us to gain deeper insights into how digital forums can be used in class and into which teaching and learning effects

\section{REFERENCES}

Anderson, N., Duncan, B., and Pungente, J. J. (1999). "Media Education in Canada - the Second Spring," in Children and Media. Image Education Participation. Editors U. Carlsson and C. V. Feilitzen (Göteborg: UNESCO International Clearinghouse on Children and Violence on the Screen Nordicom), 139-162.

Belova, N., Chang Rundgren, S.-N., and Eilks, I. (2015). Advertising and Science Education - A Multi-Perspective Review of the Literature. Stud. Sci. Educ. 51 (2), 169-200. doi:10.1080/03057267.2015.1049444

Belova, N., Dittmar, J., Hansson, L., Hofstein, A., Nielsen, J. A., Sjöström, J., et al. (2017). "Cross-Curricular Goals and Raising the Relevance of Science Education," in Cognitive and Affective Aspects in Science Education Research. Editors K. Hahl, K. Juuti, J. Lampiselkä, J. Lavonen, and A. Uitto (Dordrecht: Springer), 297-307. doi:10.1007/978-3-319-58685-4_22

Belova, N., and Eilks, I. (2015). Learning with and about Advertising in Chemistry Education with a Unit on Natural Cosmetics - A Case Study. Chem. Educ. Res. Pract. 16, 578-588. doi:10.1039/c5rp00035a correspond with student motivation and learning success. From this study it is unclear how much of the findings can be explained by a novelty effect. One teacher, J. D., is using digital forums quite frequently and there seems to be no significant cooling down effect. But, to support this impression further research would be needed. Research also needs to reveal what other digital media offerings can be used in a similar way, especially from the field of social media. Finally, future research may reveal whether continuous and active use of social media in class motivates students to become more actively involved with media. Further studies should also focus on whether or not the use of social media in class promotes critical thinking skills among students. By expanding the described pedagogy to other topics, research might also reveal how much of the perception by the students was caused by the relevant context of water quality and how much by the changed pedagogy based in Internet forums. This would allow us to find out whether learners can better distinguish between media information. Ideally, they should be able to differentiate between media offerings representing mere viewpoints or opinions and those supported by evidence based on scientific facts and theories.

\section{DATA AVAILABILITY STATEMENT}

The original contributions presented in the study are included in the article/Supplementary Material, further inquiries can be directed to the corresponding author.

\section{AUTHOR CONTRIBUTIONS}

JD developed the initial idea, research and development plan, conducted the intervention, analysed the data, and drafted the first version of the manuscript. IE supervised the work, took part in the preparation of the lesson plan and guided the data collection and interpretation. Both authors contributed to the article and approved the submitted version.

Bennett, S., Maton, K., and Kervin, L. (2008). The 'digital Natives' Debate: a Critical Review of the Evidence. Br. J. Educ. Techn. 39 (5), 775-786. doi:10.1111/j.14678535.2007.00793.x

Bingimlas, K. A. (2009). Barriers to the Successful Integration of ICT in Teaching and Learning Environments: A Review of the Literature. Eurasia J. Math. Sci. Techn. Educ. 5 (3), 235-245. doi:10.12973/ejmste/75275

Bitkom, (2016). Digitale Schule - Vernetztes Lernen. Available at: https://www. bitkom.org/Bitkom/Publikationen/Digitale-Schule-und-vernetztes-Lernen. html [Accessed July 15, 2021]. (in German).

Bodner, G. M., MacIsaac, D., and White, S. R. (1999). Action Research: Overcoming the Sports Mentality Approach to Assessment/evaluation. Univ. Chem. Educ. 3 (1), 31-36.

Brown, J. S., Collins, A., and Duguid, P. (1989). Situated Cognition and the Culture of Learning. Educ. Res. 18, 32-42. doi:10.3102/0013189x018001032

Chang Rundgren, S.-N., and Rundgren, C.-J. (2015). "Making Chemistry Education Relevant through Mass media," in Relevant Chemistry Education. Editors I. Eilks and A. Hofstein (Rotterdam: Sense), 205-218. doi:10.1007/97894-6300-175-5_11 
Childs, P. E., Hayes, S. M., and O’Dwyer, A. (2015). “Chemistry and Everyday Life: Relating Secondary School Chemistry to the Current and Future Lives of Students," in Relevant Chemistry Education. Editors I. Eilks and A. Hofstein (Rotterdam: Sense), 33-54. doi:10.1007/978-94-6300-175-5_3

Cole, J., Watkins, C., and Kleine, D. (2016). Health Advice from Internet Discussion Forums: How Bad Is Dangerous? J. Med. Internet Res. 18, e4. doi:10.2196/jmir.5051

Dittmar, J., and Eilks, I. (2015). Internetforen - Eine bislang kaum erschlossene Quelle für den naturwissenschaftlichen Unterricht. Math. Naturwiss. Unterr. 68, 213-217. (in German).

Dittmar, J., and Eilks, I. (2019). Secondary School Students and Internet Forums-A Survey of Student Views Contrasted with an Analysis of Internet Forum Posts. Educ. Sci. 9 (121), 1-14. doi:10.3390/ educsci9020121

Donelan, H. (2014). Social media for Professional Development and Networking Opportunities in Academia. J. Further High. Educ. 40, 706-729. 10.1080/ 0309877x.2015.1014321.

Eilks, I. (2018). Action Research in Science Education: A Twenty-Years Personal Perspective. Action Res. Innov. Sci. Educ. 1 (1), 3-14. doi:10.12973/arise/98909

Eilks, I., and Ralle, B. (2002). "Participatory Action Research in Chemical Education," in Research in Chemical Education - What Does This Mean? Editors B. Ralle and I. Eilks (Aachen: Shaker), 87-98.

Gikas, J., and Grant, M. M. (2013). Mobile Computing Devices in Higher Education: Student Perspectives on Learning with Cellphones, Smartphones \& Social media. Internet Higher Educ. 19, 18-26. doi:10.1016/ j.iheduc.2013.06.002

Gutefrage.net (2021). Welches Wasser Trinkt Ihr? Leitungswasser Oder Gekauftes? [What kind of water do you drink? Tap water or bought?]. Available at: https:// www.gutefrage.net/frage/welches-wasser-trinkt-ihr-leitungswasser-oder-gekauftes. [Accessed December 10, 2021]. (in German). doi:10.1016/j.iheduc.2013.06.002

Hechter, R. P., and Vermette, L. A. (2013). Technology Integration in K-12 Science Classrooms: An Analysis of Barriers and Implications. Themes Sci. Techn. Educ. 6 (2), 73-90.

Hobbs, R. (1998). The Seven Great Debates in the Media Literacy Movement. J. Comm. 48, 16-32. doi:10.1111/j.1460-2466.1998.tb02734.x

Hobbs, R., and Jensen, A. (2009). The Past, Present, and Future of media Literacy Education. J. Media Lit. Educ. 1 (1), 1-11.

Junco, R., Heiberger, G., and Loken, E. (2011). The Effect of Twitter on College Student Engagement and Grades. J. Comp. Ass. Learn. 27 (2), 119-132. doi:10.1111/j.1365-2729.2010.00387.x

Krutka, D. G., and Carpenter, J. P. (2016). Why Social media Must Have a Place in Schools. Kappa Delta Pi Rec. 52, 6-10. doi:10.1080/ 00228958.2016.1123048

Lazarowitz, R., and Hertz-Lazarowitz, R. (1998). "Cooperative Learning in the Science Curriculum," in International Handbook of Science Education. Editors B. J. Fraser and K. G. Tobin (Dordrecht: Springer), 449-469. doi:10.1007/97894-011-4940-2_26

Lewis, R. S. (2021). Technology, media Literacy, and the Human Subject: A Posthuman Approach. United Kingdom: Open Book Publishers. doi:10.11647/OBP.0253

Li, J., and Greenhow, C. (2015). Scholars and Social media: Tweeting in the Conference Backchannel for Professional Learning. Educ. Media Int. 52, 1-14. doi:10.1080/09523987.2015.1005426

Liu, Y. (2010). Social Media Tools as a Learning Resource. J. Educ. Techn. Dev. Exchange 3 (1), 101-114. doi:10.18785/jetde.0301.08

Mao, J. (2014). Social media for Learning: A Mixed Methods Study on High School Students' Technology Affordances and Perspectives. Comput. Hum. Behav. 33, 213-223. doi:10.1016/j.chb.2014.01.002

Marks, R., and Eilks, I. (2009). Promoting Scientific Literacy Using a Socio-Critical and Problem-Oriented Approach to Chemistry Teaching: Concept, Example, Experiences. Int. J. Environ. Sci. Educ. 4 (3), 231-245.

Marks, R., and Eilks, I. (2010). Research-based Development of a Lesson Plan on Shower Gels and Musk Fragrances Following a Socio-Critical and ProblemOriented Approach to Chemistry Teaching. Chem. Educ. Res. Pract. 11, 129-141. doi:10.1039/c005357k

Mayring, P., (2000). Qualitative Content Analysis. Forum Qual. Soc. Res., 1(2), Art. 20, 2000 . Available at: http://www.qualitative-research.net/index.php/fqs/ article/view/1089/2386 [Accessed July 15, 2021].
Medienpädagogischer Forschungsverbund Südwest, (2016). JIM-studie 2016. Available at: www.mpfs.de/fileadmin/files/Studien/JIM/2016/JIM_Studie_ 2016.pdf [Accessed July 15, 2021]. (in German).

Murphy, J., and Lebans, R. (2008). Unexpected Outcomes: Web 2.0 in the Secondary School Classroom. Int. J. Techn. Teach. Learn. 4 (2), 134-147.

OECD, (2018). PISA 2018 Assessment and Analytical Framework. Available at: https://www.educacionyfp.gob.es/dam/jcr:44142ea4-8d69-4ffd-9e72c301f144f9cb/pisa\%202018\%20frameworks.pdf [Accessed November $15,2021]$.

OECD, (2005). The Definition and Selection of Key Competencies. Available at: https://www.oecd.org/pisa/35070367.pdf [Accessed July 15, 2021].

Raymond, E. S., and Moen, R., (2014). How to Ask Questions the Smart Way 2014. Available at: ttyl.net/smartquestions_de.html\#intro [Accessed July 15, 2021] (in German).

Reid, G., and Norris, S. P. (2016). Scientific media Education in the Classroom and beyond: a Research Agenda for the Next Decade. Cult. Stud. Sci. Educ. 11, 147-166. doi:10.1007/s11422-015-9709-1

Schaumburg, H., and Issing, L. J. (2004). "Lernpsychologische und didaktische Aspekte des Online-Lernens," in Online-Lernen und Weiterbildung. Editor D. Meister (Wiesbaden: VS), 77-90. (in German). doi:10.1007/978-3-322-80918-6_5

Schmidt, J.-H., and Taddicken, M. (2017). Handbuch Soziale Medien. Wiesbaden: Springer. (in German).

Selwyn, N. (2012). "Social media in Higher Education," in The Europa World of Learning. Editor A Gladman. 62nd edition (London: Routledge), 3-7.

Sevian, H., and Bulte, A. M. W. (2015). "Learning Chemistry to Enrich Students' Views on the World They Live in," in Relevant Chemistry Education. Editors I. Eilks and A. Hofstein (Rotterdam: Sense), 55-78. doi:10.1007/978-94-6300175-5_4

Tappwater, (2019). Can I Drink the Tap Water in Germany. Available at: https:// tappwater.co/en/can-i-drink-tap-water-in-germany-2/[Accessed July 15, 2021.]

The Local, (2019). Wasserwende: Germany Urges More People to Drink Tap Water to Protect Environment. Available at: https://www.thelocal.de/20190815/wasserwendegermany-urges-more-people-to-drink-tap-water-to-protect-environment [Accessed July 15,2021$]$.

UBA, (2018). Drinking Water in Germany Again Rated "Very Good". Available at: https://www.umweltbundesamt.de/en/press/pressinformation/drinking-waterin-germany-again-rated-very-good [Accessed July 15, 2021].

UNESCO, (2011). Media and Information Literacy Curriculum for Teachers. Available at: unesdoc.unesco.org/images/0019/001929/192971e.pdf [Accessed July 15,2021$]$.

UNESCO, (2013). Media and Information Literacy: Policy and Strategy Guidelines. Available at: unesdoc.unesco.org/ark:/48223/pf0000225606 [Accessed July 15, 2021].

UNESCO, (2008), Wissen im Web. Available at: https://www.unesco.de/fileadmin/ medien/Dokumente/unesco-heute/unesco-heute-1-08.pdf [Accessed July 15, 2021] (in German).

Uusiaautti, S., and Määttä, K. (2014). I Am No Longer Alone - How Do university Students Perceive the Possibilities of Social media? Int. J. Adolescence Youth 19 (3), 293-305. 10.1080/02673843.2014.919600.

Conflict of Interest: The authors declare that the research was conducted in the absence of any commercial or financial relationships that could be construed as a potential conflict of interest.

Publisher's Note: All claims expressed in this article are solely those of the authors and do not necessarily represent those of their affiliated organizations, or those of the publisher, the editors and the reviewers. Any product that may be evaluated in this article, or claim that may be made by its manufacturer, is not guaranteed or endorsed by the publisher.

Copyright $\odot 2022$ Dittmar and Eilks. This is an open-access article distributed under the terms of the Creative Commons Attribution License (CC BY). The use, distribution or reproduction in other forums is permitted, provided the original author(s) and the copyright owner(s) are credited and that the original publication in this journal is cited, in accordance with accepted academic practice. No use, distribution or reproduction is permitted which does not comply with these terms. 